\title{
Application of BIM Technology in Design and Construction of High-Rise Prefabricated Steel Structure Green Residential Building
}

\author{
Weng Mei, Li Jianghua* \\ Henan Polytechnic Institute, Nanyang, Henan, China \\ *Corresponding Author.
}

\begin{abstract}
:
BIM Technology is a major innovation in the construction industry. The project informatization based on BIM Technology will be one of the effective ways to improve the efficiency and profit of construction industry. Taking a indemnificatory housing project as an example, this paper studies the application of BIM Technology in the deepening design and construction of steel structure. Aiming at the creation of complete BIM, this paper proposes an integrated BIM construction framework for the whole life cycle of buildings. By studying the basic structure, modeling process, application architecture and key modeling technologies of integrated BIM, a prototype system of BIM data integration and service platform is developed. The feasibility and applicability of bimisp are verified through the practical application of affordable housing project. In the application of BIM Technology, multiple BIM software and data fusion technology are used to improve the efficiency and accuracy of the system. The test results show that: using BIM platform to give full play to the advantages of the software, improve the efficiency of in-depth design and on-site installation of steel structure project, which can provide reference for the application of BIM Technology in prefabricated buildings in the future.
\end{abstract}

Keywords: BIM Technology, Life Cycle, Data Integration and Service Platform, Prefabricated Building.

\section{INTRODUCTION}

Prefabricated steel structure residence is a new type of "green, energy saving and environmental protection" building vigorously promoted in recent years in China. Compared with traditional reinforced concrete buildings, prefabricated steel structure mainly has the following advantages [1-2]. Steel members are suitable for industrial production. The design, production, construction and installation of steel members can be integrated through BIM platform, changing "field construction" into "factory manufacturing and field installation" [3]. The installation of steel members can achieve dry operation on site, with high installation efficiency and short construction period; in addition, the steel structure materials can be recycled.

Based on the advantages of prefabricated steel structure buildings, the relevant departments in China have issued more supporting policies [4-5]. Liuzhou housing project, the first pilot project of prefabricated steel structure high-rise residential building in Guangxi, is undertaken by the Fifth Construction Engineering Co., Ltd. of Guangxi construction engineering group [6-7]. BIM Technology is fully applied in the deepening 
design and construction of steel structure, and good results have been achieved.

\section{PROJECT OVERVIEW}

Lianhuacheng affordable housing project in Liuzhou city is located on Liushi Road, Yufeng District, Liuzhou City, northwest of the intersection of Lianhua overpass ramp and Liushi road. There are 10 single buildings, with a total construction area of $144785.72 \mathrm{~m}^{2}$, including $103173.23 \mathrm{~m}^{2}$ above ground and $41612.49 \mathrm{~m}^{2}$ underground [8]. The main structure of the above ground part of the single building adopts steel structure, the structural system of $1 \sim 9$ buildings adopts flat column H-beam frame + support structure system; the structural system of 10 buildings adopts flat column H-beam frame structure system; this project is the first trial site Project of prefabricated steel structure high-rise residential building in Guangxi, with the total weight of steel structure of about 10000 tons.

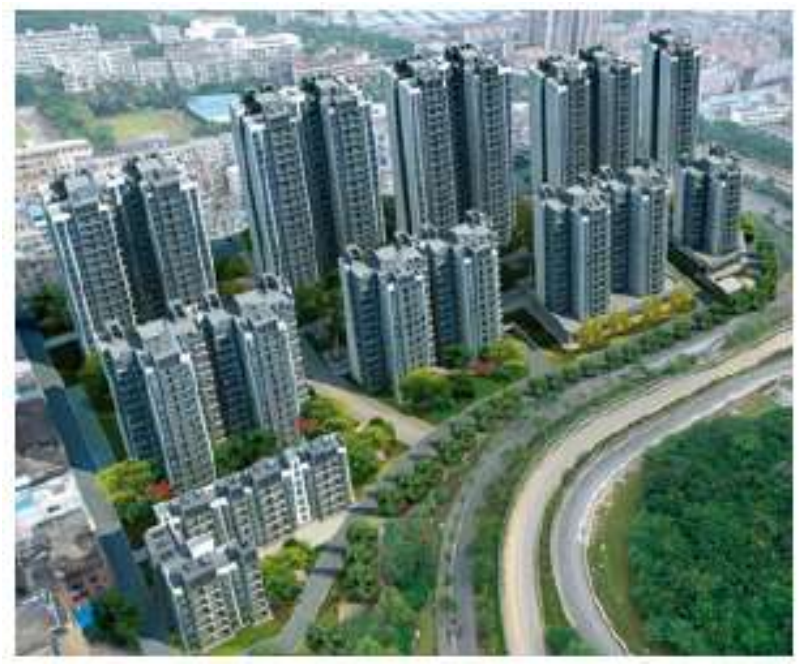

Fig 1: Overall rendering of Liuzhou affordable housing project

The key points and difficulties of the project are as follows [9-10]:

(1) The project is the first prefabricated residential project in Guangxi, which can be used for reference;

(2) For example, the steel structure and water and electricity pipelines have more cross interference, so the construction is greatly affected;

(3) The joint between the exterior wall panel and the steel beam column joint is the weak link of waterproof, and the stress of the joint is complex. In the deepening design of steel structure, it is necessary to carry out more detailed design and treatment for the joint of steel beam and column;

(4) The construction period of the project is tight, and the steel structure processing needs a certain processing time, so the steel structure deepening design needs to be fast, accurate and efficient, so as to buy time for the processing and installation of steel members;

(5) There are 10 residences in this project, the weight of steel members is up to 10000 tons, the steel structure installation workload is large, and the installation work is wide, and the installation is difficult;

(6) As the project belongs to the indemnificatory housing project, it is highly concerned by all parties in the society, with tight construction period and strict requirements.

In view of the above reasons, it is necessary to organize scientifically and prepare carefully, especially to make full use of BIM Technology, establish visual model, minimize the collision, interference, design change 
and other problems that may occur in the construction project, and make full use of BIM Technology to simulate the installation and use conditions, so as to provide basic parameters for the deepening design of steel structure.

\section{APPLICATION OF BIM TECHNOLOGY IN DEEPENING DESIGN}

\subsection{BIM Technology Application Process}

In the detailed design of steel structure of this project, BIM software and main process are as follows:

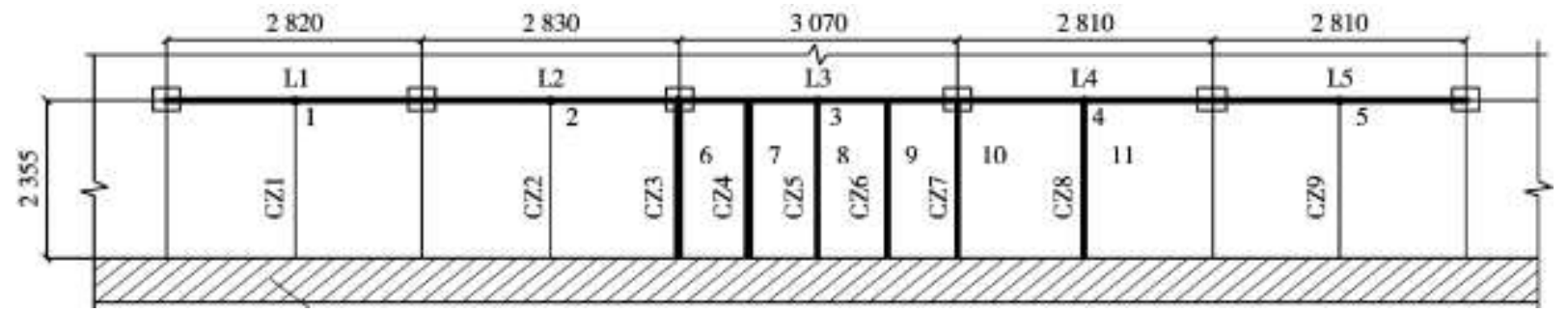

Fig 2: Project engineering sketch

3.2 Establishing steel structure model

Using the first mock exam of Tekla Structures allows multiple people to operate the same model at the same time, the 3D model of the steel structure residence of the project is established quickly, and the information needed is input into the BIM model, such as the diameter of bolt hole, the material of the component, and the BIM number of the zero component.

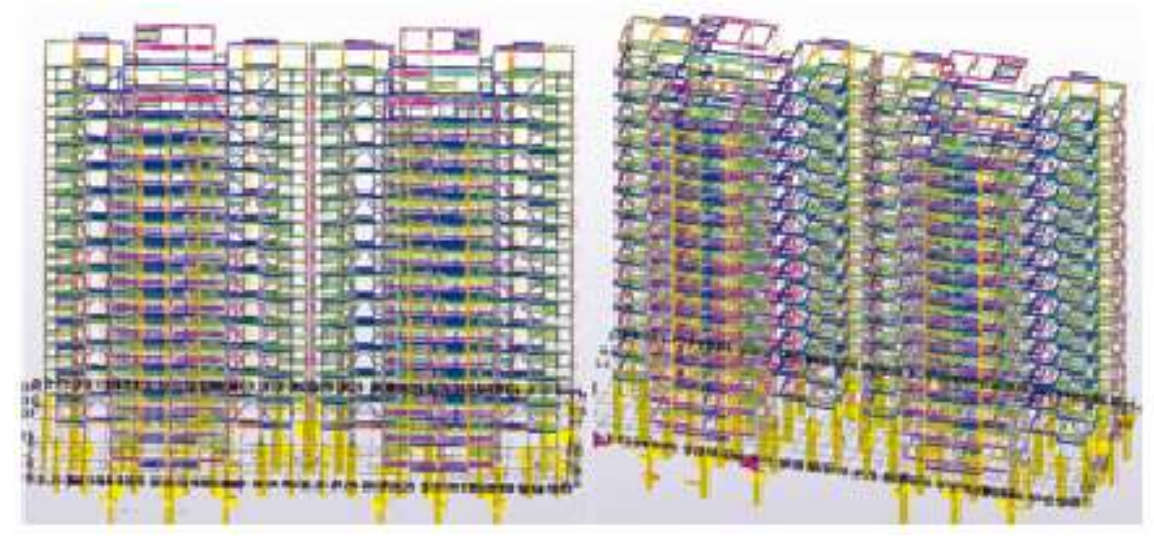

Fig 3: BIM model of steel structure residence

\subsection{Overall stress analysis}

In Tekla Structures software, after the model is established and checked correctly, the main stress components are exported to dxf file, and then the file is imported into MIDAS Gen software for overall stress analysis. This paper mainly analyzes the strength, stiffness and stability of steel structure under permanent load, wind load and earthquake load. 
Article History: Received: 20 October 2020, Revised: 15 November 2020, Accepted: 08 December 2020, Publication: 28 February 2021

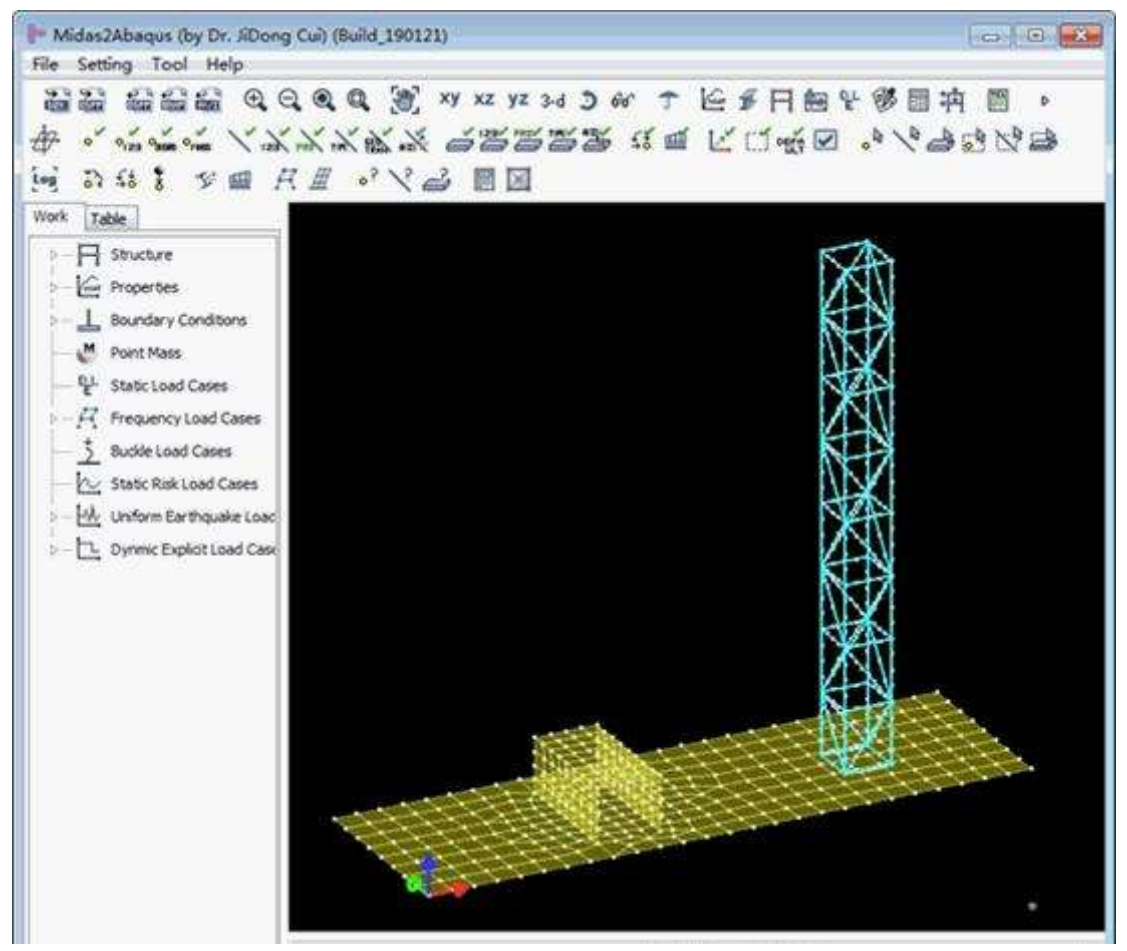

Fig 4: Import steel structure housing model into Midas Gen software
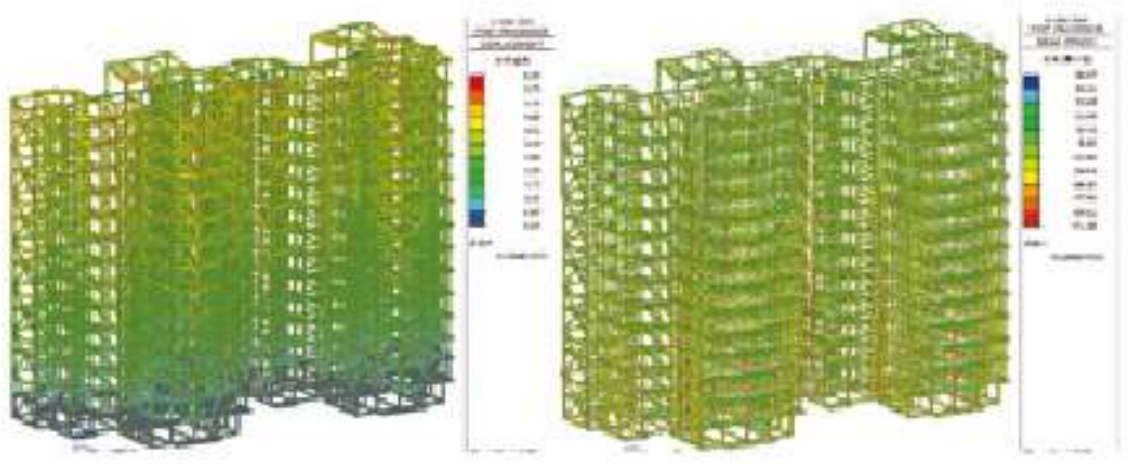

Fig 5: Cloud picture of stress analysis results of steel structure residence

\subsection{Establish node model}

The connection node of steel column and steel beam is established in Solid Works. The software uses parametric and dimension-driven modeling methods. If one of the parameters is modified, the associated dimensions and features will be automatically changed and re-modeled. By using these characteristics, the connection node of steel column and steel beam can be modified and optimized conveniently in Solid Works.

In order to further study the prefabricated steel structure residence, Guangxi Construction Engineering Group No.5 Construction Engineering Co., Ltd. also established a small prefabricated steel structure residence experimental building, which was used to test the connection of different steel columns and steel beams, optimized the connection nodes of steel columns and steel beams, and finally developed a new type of bolted welding connection node. After preliminary analysis, the optimized joint has simpler manufacturing process (welding workload is about $50 \%$ before optimization), higher manufacturing efficiency and more reasonable stress than that before optimization. 


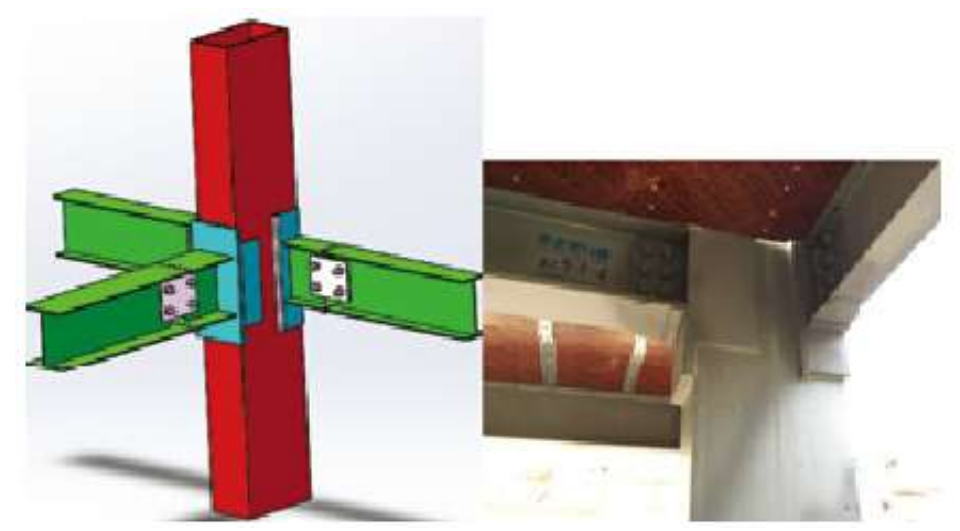

Fig 6: Optimized connection node of steel column and steel beam

\subsection{Mechanical analysis of detail (local) of connection nodes}

The steel structure connection nodes are imported into ANSYS WorkBench software, and the detailed (local) stress analysis of the connection nodes is carried out. In the analysis, if the local stress or deformation is found to be too large or beyond the scope of specification and design requirements, SolidWorks software is used to re-establish the model of changing the size of the joint, and then imported into ANSYS WorkBench for analysis until the optimized result meets the specification and design requirements.

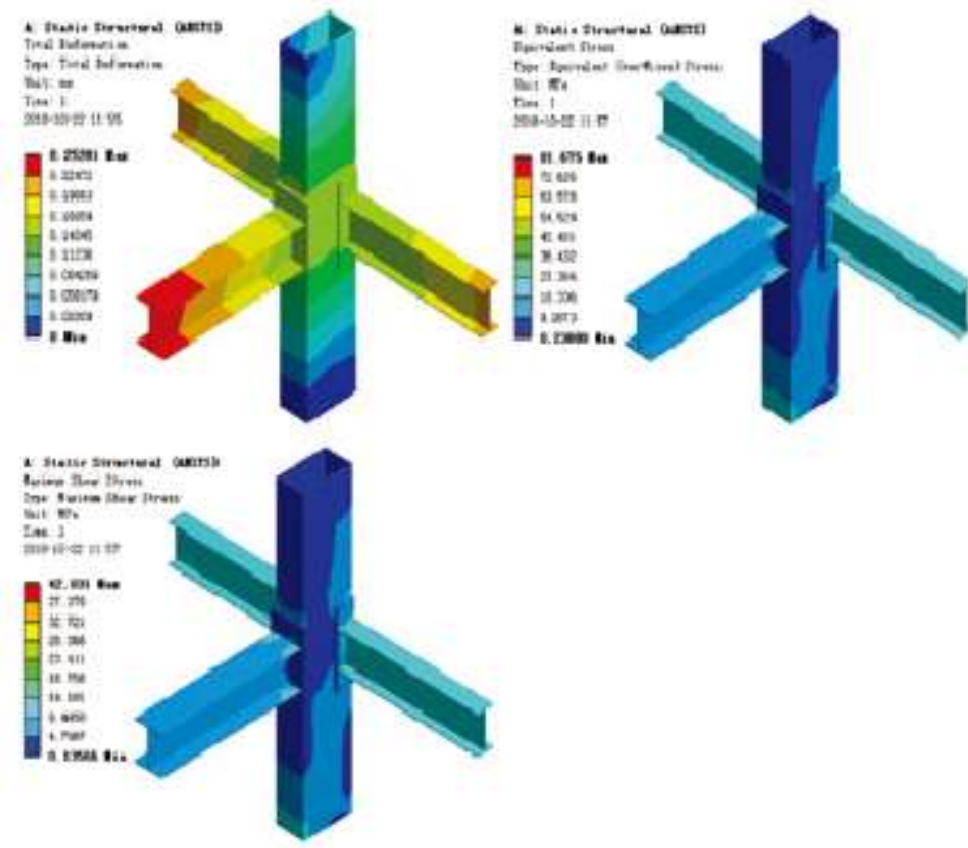

Fig 7: Cloud chart of stress analysis of steel column steel beam connection joint 3.6 Output two-dimensional machining drawing by Tekla Structures and SolidWorks

Tekla Structures and SolidWorks both have the function of collision check (interference check), which can avoid the loss caused by major mistakes and greatly improve the drawing efficiency and the installation efficiency of steel members on site.

In addition, Tekla Structures and Solid Works both have the ability to convert 3D models into 2D machining drawings, and their functions are relatively powerful. They can also export 2D machining drawings generated by them to DWG files for convenient communication.

After collision (interference) inspection and other audits, the 3D model is output as 2D machining 
drawings, which are related to the 3D model. If the 3D model is modified, the 2D machining drawings will be automatically changed, thus ensuring the accuracy and consistency of the drawings.

Before the hoisting of steel members, Tekla structures is used to simulate the construction, improve the construction technology, and list the key construction control nodes to ensure the construction safety. For example, Tekla structures is used to calculate the weight of the largest hoisting steel member, and a more economical tower crane is selected in combination with the special construction scheme of steel member installation to meet the safety and construction needs.

Key points of steel member installation construction:

(1) Before lifting the first floor steel column, clean the foundation, adjust the foundation elevation (bolts and nuts), and then install it;

(2) Before lifting the column, draw a horizontal line $500 \sim 1000 \mathrm{~mm}$ upward from the column bottom plate, so as to recheck the plane elevation datum before and after installation and fixation;

(3) The perpendicularity of steel column should be checked at the same time of installation to prevent large cumulative error in production. The checking time should be selected in the morning when the temperature is relatively constant;

(4) When the steel beam is installed, it shall be subject to no deformation after lifting, and it shall be balanced and easy to release the rope. The angle of the sling shall not be less than $60^{\circ}$ and the binding must be firm. The selection of the sling must be determined by calculation;

(5) The welding sequence of the joint should be extended symmetrically from the middle to the periphery in the plane. The welding of multi-layer beam should follow the principle of welding the top layer beam first, then the bottom layer beam, and then the secondary top layer beam and secondary layer beam. The column butt weld can be welded first or later. Beam and column shall be welded symmetrically on both sides of the column by two welders in a row. Electric welders shall weld in strict accordance with the assigned welding sequence and shall not change by themselves.

\section{CONCLUSION}

The state and local governments have continuously issued a series of policies to encourage and promote the development of prefabricated buildings, so as to promote the upgrading of the industrial structure of the construction industry and achieve high-quality and green development. Steel structure has many advantages, such as high recycling rate, good seismic performance, convenient construction and so on. In a long time in the future, the number of steel structure buildings (including prefabricated steel structure residential buildings and steel structure public buildings) will be more and more. As the high-quality development of prefabricated building is inseparable from BIM Technology, with the development of prefabricated building, BIM Technology, especially the joint use of multiple BIM software, will be more and more widely used in prefabricated building.

\section{REFERENCES}

[1] Peng, Y., Lin, J. R., Zhang, J. P., \& Hu, Z. Z., (2017). A hybrid data mining approach on BIM-based building operation and maintenance. Building and Environment, 126(dec.), 483-495. 
[2] Lee, S. I., Bae, J. S., \& Cho, Y. S., (2012). Efficiency analysis of set-based design with structural building information modeling (s-BIM) on high-rise building structures. Automation in construction, 23(May), p.2032.

[3] Diao, Y., Kato, S., \& Hiyama, K., (2011). Development of an optimal design aid system based on building information modeling. Building Simulation, 4(4), 315-320.

[4] Fortino, G., Messina, F., Rosaci, D., \& Sarne, G. M. L., (2019). Using blockchain in a reputation-based model for grouping agents in the internet of things. IEEE Transactions on Engineering Management, PP(99), 1-13.

[5] Zhu Y, Qiu J, Du H, et al. Simultaneous optimal design of structural topology, actuator locations and control parameters for a plate structure. Computational Mechanics, 2002, 29(2):89-97.

[6] Destain M F, Houmy K., Effects of design and kinematic parameters of rotary cultivators on soil structure. Soil and Tillage Research, 1990, 17( 3-4):291-301.

[7] Alexander H, Olaf P, Dirk K, et al. Dissecting Physiological Roles of Estrogen Receptor $\alpha$ and $\beta$ with Potent Selective Ligands from Structure-Based Design. Molecular Endocrinology(7):7.

[8] Azam F, Medapati V V P, Thangavel N, et al. Structure-Based Design, Synthesis and Molecular Modeling Studies of Thiazolyl Urea Derivatives as Novel Anti-Parkinsonian Agents. Medicinal Chemistry, 2012, 8(6):1057-1068.

[9] Wang K C., Optimal high-rigidity structure design for CNC machine tools using CAE technique. Engineering Computations, 2014, 31(8):1761-1777.

[10] Premalatha M (2008) Efficient cogeneration scheme for sugar industry. Journal of Scientific \& Industrial Research 67:239-242 